\title{
ESTRUCTURAS FLEXIBLES DE COSTOS PARA ENFRENTAR LA GLOBALIZACIÓN Y LA COMPETITIVIDAD EN LAS EMPRESAS
}

\section{FLEXIBLE COST STRUCTURES TO OVERCOME THE GLOBALIZATION AND COMPETITIVENESS IN THE COMPANIES}

\section{Agustin Rodríguez Chávez *}

Docente Asociado de la Facultad de Ciencias Contables, UNMSM

[Recepción: Marzo de 2010 / Conformidad: Abril de 2010]

\section{RESUMEN}

La actual tendencia mundial señala que las empresas para enfrentar las exigencias de la competencia global originada por la permanente innovación tecnológica y la mayor exigencia del cliente, en calidad y los precios de los productos, están orientando sus recurso, conocimientos y esfuerzos en hacer que sus procesos de negocios, procesos productivos y organización sean flexibles para lograr una rápida respuesta a esas exigencias.

Pero los costos originados por esa respuesta están obligando a las empresas a acceder a la innovación tecnológica a través de servicios de maquila y tercerización.

Sin embargo, las estructuras de costos no han sido adecuadas para reconocer estos cambios y proporcionar una mejor visión de los procesos y cálculo de costos para LA GESTION, REGISTRO Y CONTROL DE COSTO.

El propósito del presente artículo es el de proponer una ESTRUCTURA FLEXIBLE DE COSTOS que responda las exigencias DEL MERCADO, LA EMPRESA Y EL CLIENTE. Una estructura que permita recoger el comportamiento y los costos asociados a esos procesos efectuados por terceros en la diversas modalidades.

Palabras clave: Innovación, calidad, procesos productivos, procesos de negocio, maquila, tercerización, estructura de costos.

\begin{abstract}
The present world-wide tendency indicates that the companies to face the exigencies of the global competition originated by the permanent technological innovation and the greater exigency of the client, in quality and the prices of products, are orienting their resource, knowledge and efforts in doing that their processes of businesses, processes productive and organization are flexible to obtain a fast answer to those exigencies. But the costs originated by that answer are forcing the companies to accede to the technological innovation through services of manufacturing, external processes and outsourcing. Nevertheless the structures of costs have not been adapted to recognize these changes and provide a better visition of the processes and calculation of costs for the MANAGEMENT, REGISTRY AND CONTROL OF COSTHE.

The intention of this article is to propose a FLEXIBLE STRUCTURE OF COSTS that responds the exigencies OF the MARKET, the COMPANY AND the CLIENT. A structure that allows to pick up the behavior and the costs associated to those processes conducted for diverse modalities.
\end{abstract}

Key words: Innovation, quality, production processes, business processes, assembly, outsourcing, cost structure

\footnotetext{
Maestría en costos y presupuestos, contador público colegiado certificado. Docente Asociado de la Facultad de Contabilidad Especialista en Costos. E-mail: a.rodriguez@econsultingkfb.net
} 


\section{INTRODUCCIÓN}

El globalización ha provocado un impacto significativo en la economía del mundo pues ésta es un hecho y está comenzando a mostrar sus efectos, algunos muy positivos pero otros también negativos. Es así que las empresas industriales deben ser capaces de enfrentar los retos que este nuevo contexto implica, teniendo presente que tanto la productividad como la competitividad son de vital importancia para este encuentro.

La innovación en la tecnología de producción y procesos es un factor que ha conllevado a que en estos últimos años las empresas industriales compitan ferozmente por mantenerse en el mercado o abarcar nuevos segmentos; por ejemplo: comprando maquinarias modernas, contratando especialistas en costos, despidiendo personal considerado como gasto, entre otros factores que las impidan crecer como empresa. No obstante, existen empresas que no tienen la posibilidad de adaptarse ha este mundo tan competitivo e innovador, pues no cuentan con los recursos necesarios para comprar activos o contratar personal especializado para obtener una mayor productividad. Estas son las empresas que están evaluando constantemente como el costo de esta innovación incrementa el riesgo del negocio, teniendo que recurrir a la tercerización o la maquila para poder competir dignamente.

Pero, ¿qué es el outsourcing o tercerización? Es un servicio que brindan empresas o personas naturales especializadas ajenas al negocio a las empresas que lo soliciten. $\mathrm{Al}$ suceder esto, las empresas en desventaja están creando nuevas actividades económicas bajo diversas modalidades de contratación y uso; incluyendo así un nuevo elemento a su estructura de costos. Sin embargo, se puede apreciar cómo una empresa portadora de una alta tecnología de INVESTIGACIÓN, DESARROLLO YDISEÑO DE PRODUCTOS accede también al mercado con productos manufacturados en parte o enteramente por terceros. Del mismo modo, naciones enteras se han orientado a la actividad de servicios de fabricación a través de las modalidades de maquila o tercerización.

Es así que surge la necesidad de elaborar una estructura flexible de costos de modo que con esta se pueda enfrentar a la globalización, innovación y a sus competidores de forma eficiente, oportuna, a un precio razonable y con alta calidad en sus productos; cumpliendo así con las expectativas del mercado.

El comportamiento de las estructuras de costos en los años se han vuelto muy dinámicas y con grandes cambios especialmente en la tecnología y la mano de obra. 


\section{OBJETIVOS}

- Definir los conceptos relacionados con una estructura de costos.

- Señalar las normas relacionadas con la estructura de costos.

- Presentar las conclusiones.

\section{CONCEPTOS RELACIONADOS}

\section{Estructura de Costos}

La tradicional estructura de costos está conformada por 3 elementos, estos son: los costos de materiales directos, costos de mano de obra directa de producción y costos indirectos de producción.

A continuación, se analizará cada uno de estos para saber en dónde normalmente las empresas industriales incluyen los costos en que incurren para obtener un producto terminado.

- Costos de materiales directos. Estos son los costos de adquisición de todos los materiales que al final van a formar parte del objeto del costo (producto a elaborar) y que pueden ser identificados en el producto en proceso y luego en el producto terminado. Algunos ejemplos de costos de materiales directos son la tela de algodón que se utiliza para producir polos de algodón y el acero para fabricar las turbinas para la generación de energía eléctrica.

- Costos de mano de obra directa de producción. Estos costos incluyen la remuneración de toda la mano de obra que se utiliza para elaborar un producto terminado y estos pueden ser identificados en el producto en proceso y luego en el producto terminado. Algunos ejemplos incluyen salarios y prestaciones pagados a los operadores de maquinaria y a los trabajadores de la línea de ensamblado, quienes convierten los materiales directos adquiridos en productos terminados.

- Costos indirectos de producción. Son todos los costos de fabricación que se relacionan con el objeto del costo pero que no pueden ser identificados fácilmente en el producto en proceso o en el producto terminado; por ello es que generalmente; estos costos se prorratean entre todos los productos elaborados o en proceso. Algunos ejemplos incluyen suministros, materiales indirectos como lubricantes, mano de obra indirecta de fabricación como la limpieza del local, el alquiler del local, el seguro de la fábrica, la depreciación del local, entre otros.

\section{Outsourcing o Tercerización}

Es un tecnicismo proveniente de la abreviación de la frase "outside resource using" (Michel Strobel - Dynamic Outsourcing of Services, IBM Reseach 2000).

Outsourcing es la compra de bienes y servicios a proveedores externos en lugar de tener abastecimientos internos, insourcing, los cuales consisten en la generación de los mismos bienes o el suministro de los mismos servicios dentro de la organización (Contabilidad de Costos, 12. ${ }^{\text {a }}$ edición, Charles T. Horngren, 2007). Esta subcontratación de servicios busca agilizar y economizar los procesos productivos para el cumplimiento eficiente de los objetos sociales de las empresas industriales, de modo que las empresas concentren sus esfuerzos en sus actividades esenciales a fin de obtener competitividad y resultados tangibles.

Para llevar a cabo el outsourcing, es muy importante entender a fondo los costos asociados a cada producto para así tener la segu- 
ridad de que no se ha dejado ningún costo por asignar al producto en proceso o al producto terminado. Entonces se procederá a:

- Analizar en qué productos y en qué procesos la empresa es eficiente para así localizar sus puntos fuertes. Por ejemplo, una empresa textil tiene su fortaleza en la costura de la prenda pero no en el proceso de corte; entonces, deberá el servicio de corte a una empresa especializada en ello.

- Seleccionar los productos o procesos a ser evaluados para ver la posibilidad de realizar un outsourcing al área débil, con base en el análisis anterior.

- Investigar acerca de posibles empresas con las que se realizará la tercerización, tomando en cuenta su especialización y solicitar las cotizaciones respectivas y analizarlas cuidadosamente.

- Analizar las cotizaciones contra los costos internos para saber si realmente nos conviene tercerizar o no. Asimismo, se deben evaluar los riesgos que conllevan un outsourcing. Por ejemplo, dar a conocer formulas secretas, desligarse de grandes responsabilidades, pérdida de mercado, entre otras.

A continuación, se enumeran algunas actividades que comúnmente son objeto de tercerización:

- Logística. Área encargada de distribuir productos a clientes y obtención de materiales de proveedores.

- Tesorería. Área encargada de la liquidación de sueldos y jornales, facturación, pago a proveedores mediante emisión de cheques o transferencias

- Recursos humanos. Se encarga de la selección y capacitación del personal.

- Consultaría legal. Manejo de asuntos legales como litigios, juicios, llevados adelante por estudios de abogados especializados.
- Tecnología de la información. Investiga y desarrolla sistemas, asesoría, consultoría e informática funcional de la organización; para apoyar la automatización de toma de decisiones y procesos operativos.

- Procesos productivos. Abarca los procesos industriales parciales o completos como ensamblado, corte, confección, teñido, soldadura, entre otros procesos, así como actividades de servicios como mantenimiento de maquinarias, control de calidad, seguridad industrial, etc.

- Compra de materiales. Es la elaboración directa por parte de terceros (uno solo o varios) del producto terminado, el cual luego se venderá sin ningún proceso adicional.

- Actividades comerciales: gestión de venta, diseño de campañas promocionales y publicitarias de productos, organización de eventos, investigaciones y auditorías de mercado, etc.

\section{La maquila}

Este modelo empresarial se da cuando una empresa se compromete a producir un artículo para un tercero pero la empresa que solicitó su servicio es el que realmente lo comercializa con su propia marca. Por otro lado, en el caso de la maquila para la exportación, las empresas utilizan insumos y tecnología generalmente importados, emplean mano de obra local y destinan la producción para la exportación.

Se debe de tener en cuenta que las maquilas se clasifican en tres generaciones:

- Primera generación. Son plantas que son intensivas en trabajo no calificado y salarios bajos, y que no utilizan tecnología tan avanzada.

- Segunda generación. Son aquellas que poseen una mayor autonomía en la de- 
cisión, necesitan de maquinaria con mayor tecnología, se preocupan más por la calidad de sus productos y en ciertos casos recurren a la semi-automatización e inclusive la automatización en los procesos de producción, lo que se requiere de trabajo más calificado -más ingenieros y técnicos-.

- Tercera generación. Tienen una vinculación mayor con el desarrollo de tecnología y poseen capacidades más altas de producción.

\section{NORMAS RELACIONADAS}

\section{NIC 2: Existencias}

Párrafo 10. El costo de los inventarios comprenderá todos los costos derivados de su adquisición y transformación, así como otros costos en los que se haya incurrido para darles su condición y ubicación actuales.

Párrafo 11. El costo de adquisición de los inventarios comprenderá el precio de compra, los aranceles de importación y otros impuestos (que no sean recuperables posteriormente de las autoridades fiscales), los transportes, el almacenamiento y otros costos directamente atribuibles a la adquisición de las mercaderías, los materiales o los servicios. Los descuentos comerciales, las rebajas y otras partidas similares se deducirán para determinar el costo de adquisición.

Párrafo 12. Los costos de transformación de los inventarios comprenderán aquellos costos directamente relacionados con las unidades producidas, tales como la mano de obra directa. También comprenderán una parte, calculada de forma sistemática, de los costos indirectos, variables o fijos, en los que se haya incurrido para transformar las materias primas en productos terminados. Son costos indirectos fijos los que permanecen relativamente constantes, con independencia del volumen de producción, tales como la amortización y mantenimiento de los edificios y equipos de la fábrica, así como el costo de gestión y administración de la planta. Son costos indirectos variables los que varían directamente, o casi directamente, con el volumen de producción obtenida, tales como los materiales y la mano de obra indirecta.

Párrafo 15. Se incluirán otros costos, en el costo de los inventarios, siempre que se hubiera incurrido en ellos para dar a los mismos su condición y ubicación actuales. Por ejemplo, podrá ser apropiado incluir, como costo de los inventarios, algunos costos indirectos no derivados de la producción, o los costos del diseño de productos para clientes específicos.

Párrafo 16. Son ejemplos de costos excluidos del costo de los inventarios, y por tanto reconocidos como gastos del periodo en el que se incurren, los siguientes:

(a) las cantidades anormales de desperdicio de materiales, mano de obra $u$ otros costos de producción;

(b) los costos de almacenamiento, a menos que sean necesarios en el proceso productivo, previos a un proceso de elaboración ulterior;

(c) los costos indirectos de administración que no hayan contribuido a dar a los inventarios su condición y ubicación actuales; $\mathrm{y}$

(d) los costos de venta.

Párrafo 19. En el caso de que un prestador de servicios tenga inventarios, los medirá por los costos que suponga su producción. Estos costos se componen fundamentalmente de mano de obra y otros costos del personal directamente involucrado en la prestación del servicio, incluyendo personal de supervisión y otros costos indirectos atri- 
buibles. La mano de obra y los demás costos relacionados con las ventas, y con el personal de administración general, no se incluirán en el costo de los inventarios, sino que se contabilizarán como gastos del periodo en el que se hayan incurrido. Los costos de los inventarios de un prestador de servicios no incluirán márgenes de ganancia ni costos indirectos no atribuibles que, a menudo, se tienen en cuenta en los precios facturados por el prestador de servicios.

Ley N.o 29245 - Ley que regula los servicios de tercerización $(26 / 06 / 2008)$

\section{Artículo 2. Definición}

Se entiende por tercerización la contratación de empresas para que desarrollen actividades especializadas u obras, siempre que aquellas asuman los servicios prestados por su cuenta y riesgo; cuenten con sus propios recursos financieros, técnicos o materiales; sean responsables por los resultados de sus actividades y sus trabajadores estén bajo su exclusiva subordinación.

Constituyen elementos característicos de tales actividades, entre otros, la pluralidad de clientes, que cuente con equipamiento, la inversión de capital y la retribución por obra o servicio. En ningún caso se admite la sola provisión de personal.

La aplicación de este sistema de contratación no restringe el ejercicio de los derechos individuales y colectivos de los trabajadores.

\section{Artículo 3. Casos que constituyen terceri- zación de servicios}

Constituyen tercerización de servicios, entre otros, los contratos de gerencia conforme a la Ley General de Sociedades, los contratos de obra, los procesos de tercerización externa, los contratos que tienen por objeto que un tercero se haga cargo de una parte integral del proceso productivo.

Decreto supremo N.o 006-2008-TR - Reglamento de la Ley N.o 29245 y del Decreto legislativo N.o 1038, que regulan los servicios de tercerización $(12 / 09 / 2008)$

\section{Artículo 10. Definiciones}

Para los efectos de la Ley N.o 29245 y del Decreto Legislativo N. ${ }^{\circ} 1038$, se tendrán en cuenta las siguientes definiciones:

$[\ldots]$

Empresa tercerizadora.- Empresa que lleva a cabo el servicio u obra contratado por la empresa principal, a través de sus propios trabajadores, quienes se encuentran bajo su exclusiva subordinación. Son consideradas como empresas tercerizadoras, tanto las empresas contratistas como las subcontratistas.

Tercerización.- Es una forma de organización empresarial por la que una empresa principal encarga o delega el desarrollo de una o más partes de su actividad principal a una o más empresas tercerizadoras, que le proveen de obras o servicios vinculados o integrados a la misma.

\section{Artículo 4º. Elementos característicos}

4.1. Los elementos propios de los servicios de tercerización que se encuentran regulados en el segundo párrafo artículo $2^{\circ}$ de la Ley constituyen, entre otros, indicios de la existencia de autonomía empresarial, los cuales deben ser evaluados en cada caso concreto, considerando la actividad económica, los antecedentes, el momento de inicio de la actividad empresarial, el tipo de actividad delegada y la dimensión de las empresas principal y tercerizadora. 
4.2. De acuerdo con lo previsto por el artículo $1^{\circ}$ del Decreto Legislativo, la pluralidad de clientes no será un indicio a valorar en los siguientes casos:

a) Cuando el servicio objeto de tercerización solo sea requerido por un número reducido de empresas o entidades dentro del ámbito geográfico, del mercado o del sector en que desarrolla sus actividades la empresa tercerizadora.

b) Cuando, en base a la naturaleza del servicio u obra, existan motivos atendibles para el establecimiento de pacto de exclusividad entre la empresa principal y la tercerizadora.

c) Cuando la empresa tercerizadora se encuentre acogida al régimen de la micro empresa.

4.3. Se entiende que la empresa tercerizadora cuenta con equipamiento cuando las herramientas o equipos que utilizan sus trabajadores son de su propiedad o se mantienen bajo la administración y responsabilidad de aquella.

Cuando resulte razonable, la empresa tercerizadora podrá usar equipos o locales que no sean de su propiedad, siempre que los mismos se encuentren dentro de su ámbito de administración o formen parte componente o vinculada directamente a la actividad o instalación productiva que se le haya entregado para su operación integral.

4.4. Tanto la empresa tercerizadora como la empresa principal podrán aportar otros elementos de juicio o indicios destinados a demostrar que el servicio ha sido prestado de manera autónoma y que no se trata de una simple provisión de personal, tales como la separación física y funcional de los trabajadores de una y otra empresa, la existencia de una organización autónoma de soporte a las actividades objeto de la tercerización, la tenencia y utilización por parte de la empresa tercerizadora de habilidades, experiencia, métodos, secretos industriales, certificaciones, calificaciones o, en general, activos intangibles volcados sobre la actividad objeto de tercerización, con los que no cuente la empresa principal, y similares.

\section{CONCLUSIONES}

La globalización ha forzado a las empresas industriales a replantear su tradicional estructura de costos debido a la importancia que ha tenido la tecnología e innovación en la elaboración de sus productos terminados.

Actualmente, las empresas industriales están optando por dejar algunos de sus procesos productivos en manos de personas ajenas a su negocio, esto es lo que se denomina contratar un Outsourcing.

La maquila es otro medio de producción con que las empresas industriales cuentan para encargarle por completo la elaboración de sus productos a un tercero. No obstante, estos siguen siendo los dueños del producto terminado.

La tercerización, además de hacer que las empresas disminuyan sus costos, pueden enfocar sus recursos a los puntos en los que realmente son fuertes, ya que considera que difícilmente una empresa sea óptima en todos los sectores. 


\section{REFERENCIAS BIBLIOGRÁFICAS}

1. HORNGREN, Charles T.; DATAR, Srikant M. y FOSTER, George. Contabilidad de costos, Ed. Perarson Educación, 2007.

2. NEUNER, Jhon J. W.y DEAKIN III, Edward B. Contabilidad de costos. Principios y prácticas. Tomo I, Edit. Limusa, 2007.
3. SHANK John K. y GOVINDARAJAN Vijay. Gerencia estratégica de costos, Edit. Norma, 1995.

4. http://cpn.mef.gob.pe/cpn/Libro3/ nics/NIC02_04.pdf

5. http://www.mintra.gob.pe/contenidos/archivos/prodlab/legislacion/ ley_29245.pdf

6. http://www.mintra.gob.pe/archivos/file/ normasLegales/DS 0062008 TR.pdf

7. http://www.invesca.com/2007/maquila-en-el-peru/ 